Supplement of Ocean Sci., 15, 651-668, 2019 https://doi.org/10.5194/os-15-651-2019-supplement (C) Author(s) 2019. This work is distributed under the Creative Commons Attribution 4.0 License.

(c) (1)

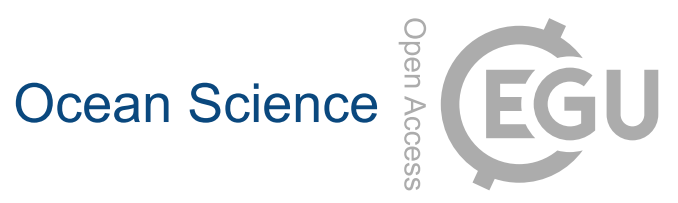

Supplement of

\title{
The long-term variability of extreme sea levels in the German Bight
}

Andreas Lang and Uwe Mikolajewicz

Correspondence to: Andreas Lang (andreas.lang@mpimet.mpg.de)

The copyright of individual parts of the supplement might differ from the CC BY 4.0 License. 


\section{S1 Comparison with the instrumental record}

Sea level observations used in this study stem from the tide gauge record at Cuxhaven (courtesy S. Dangendorf \& W. Wiechmann). Comparison of simulated and observed extreme sea level at Cuxhaven in terms of the respective highest event (Fig. A1) and their seasonal statistics relative to the long-term tidal mean high water (Fig. A2).
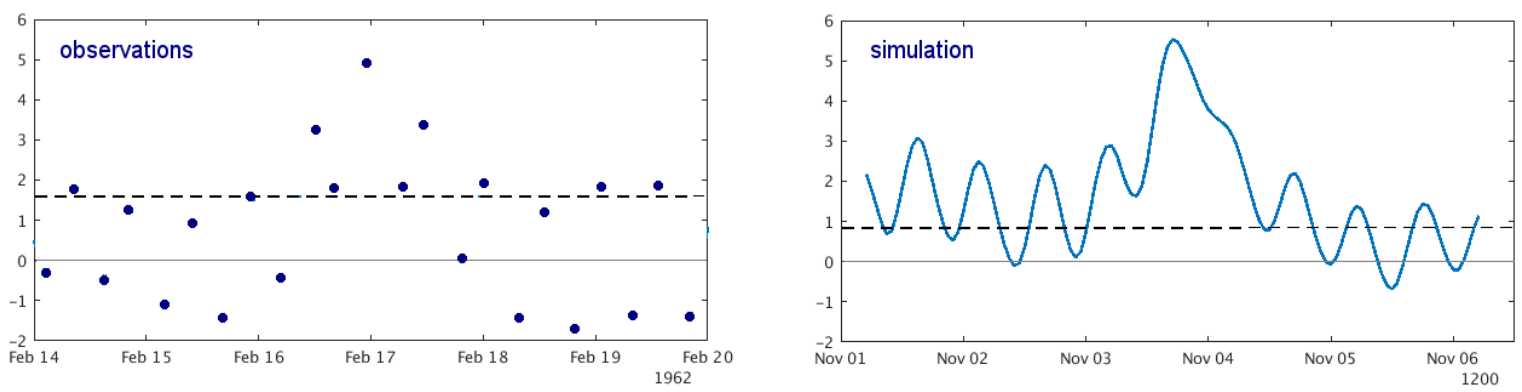

Figure S1. Time series of highest storm surge from observations (left) and model simulation (right). The dashed black line indicates the long-term mean high water. The respective long-term mean has been removed from both time series (grey line).
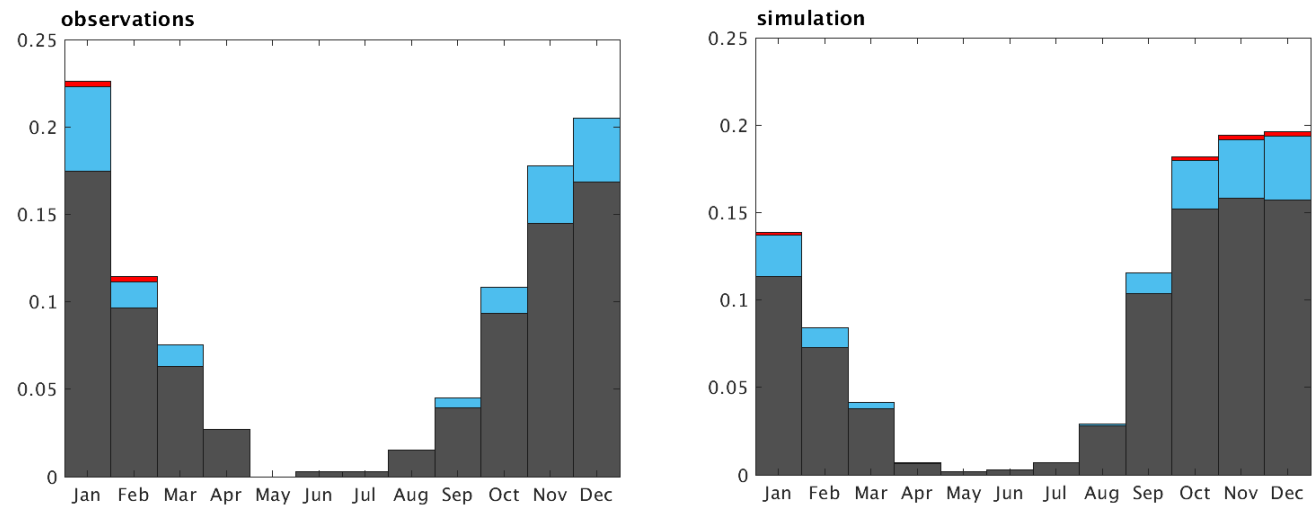

storm surges (> $1.5 \mathrm{~m}$ o MHW) heavy storm surges (> $2.5 \mathrm{~m}$ o MHW) extreme storm surges ( $>3.5 \mathrm{~m} 0 \mathrm{MHW}$

Figure S2. Relative storm surge frequency per month for observations (left) and model simulation (right) for storm surge classes following the definitions by the Federal Maritime and Hydrographic Agency (BSH). 

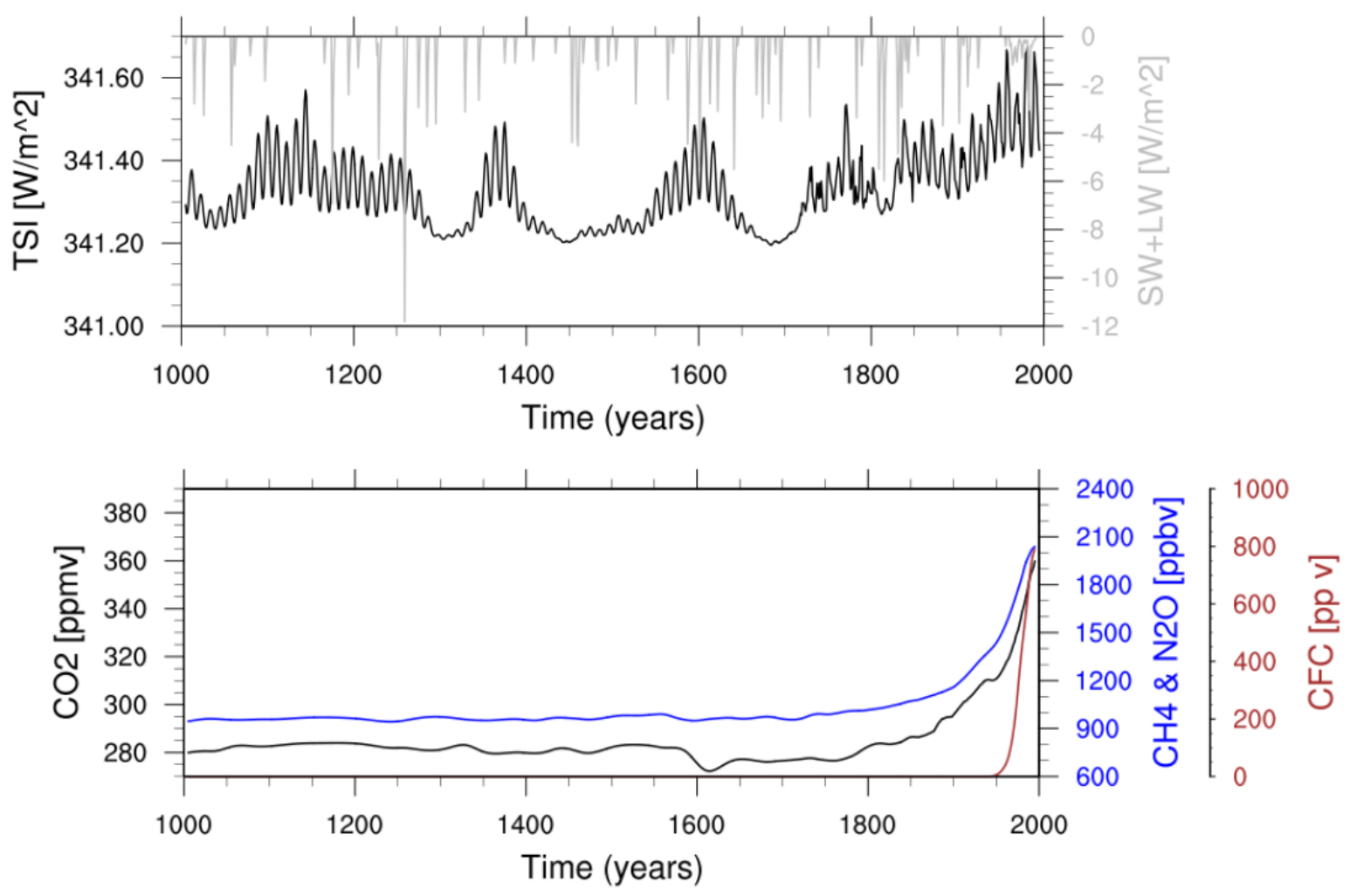

Figure S3. Top: Forcing input of annual solar irradiance [Wang et al. (2005), black line] and volcanic eruptions [Crowley et al. (2008), grey line]. Bottom: Greenhouse gas forcing, including $\mathrm{CO}_{2}$ (black), $\mathrm{CH}_{4}$ and $\mathrm{N}_{2} \mathrm{O}$ (blue) and Chlorofluorocarbons (CFC, dark red). 


\section{S3 Downscaling simulations and sources of variability}

In order to investigate the contributions of external forcing and natural variability on ESL variations, as well as effect of the downscaling process on ESL variability, two additional experiments have been performed (see Table A1).

First, to analyze the contribution of external forcing and natural variability, we have - additional to the downscaling shown in

5 the main text (experiment 011) - downscaled a second member of the parent global Last-Millennium simulations ('past1000r1', see Moreno-Chamarro et al. (2017)), covering the period 1400-1850 (experiment 012), with the first 100 years again used as spin-up. While the ESL statistics in terms of a quantile-quantile plot are comparable, the two downscalings show different temporal ESL variations, indicating that the externally forced variability is small compared to the natural variability.

Table S1. Downscaling simulations used in this study

\begin{tabular}{lll}
\hline run ID & parent GCM simulation (MPI-ESM) & time period \\
\hline 010 & past1000r2 + historicalr4 & $1500-2000$ (+100 year spin-up) \\
011 & past1000r2 + historicalr4 & $1000-2000(+100$ year spin-up) \\
012 & past1000r1 & $1500-1850$ (+100 year spin-up) \\
\hline
\end{tabular}
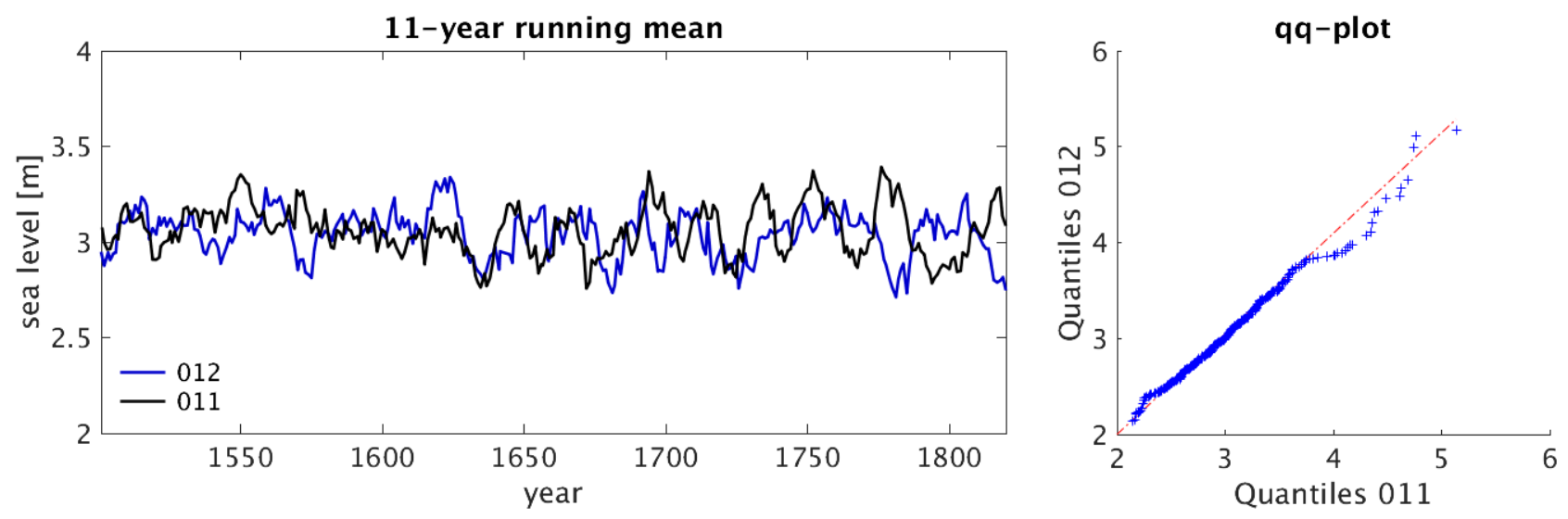

Figure S4. Comparison of ESL at Cuxhaven between runs 011 and 012 for the years 1500-1850. Left: Time series for 11 -year running means. Right: Quantile-Quantile plot.

Second, to investigate the effect of the downscaling process on ESL variability, the global PMIP3 simulation 'past1000r2' (1000-1850; Moreno-Chamarro et al., 2017) and the subsequent 'historicalr4' (1850-2000) have been downscaled twice, once over one continuous 1000 year simulation (1000-2000AD.; experiment 011 ; used for results shown in the main text), and once over the second 500 years (1500-2000AD.; experiment 010 ) with slightly different initial conditions. Both simulation are preceded by a 100 year long spin-up. An overview of the downscaling simulations is given in Table A1.

Although there is a tendency towards higher extremes in 010, especially for return periods greater than 30 years, the main 15 features of long-term variability and spectral characteristics are not affected by the downscaling (Fig. A5). Nonetheless, the 

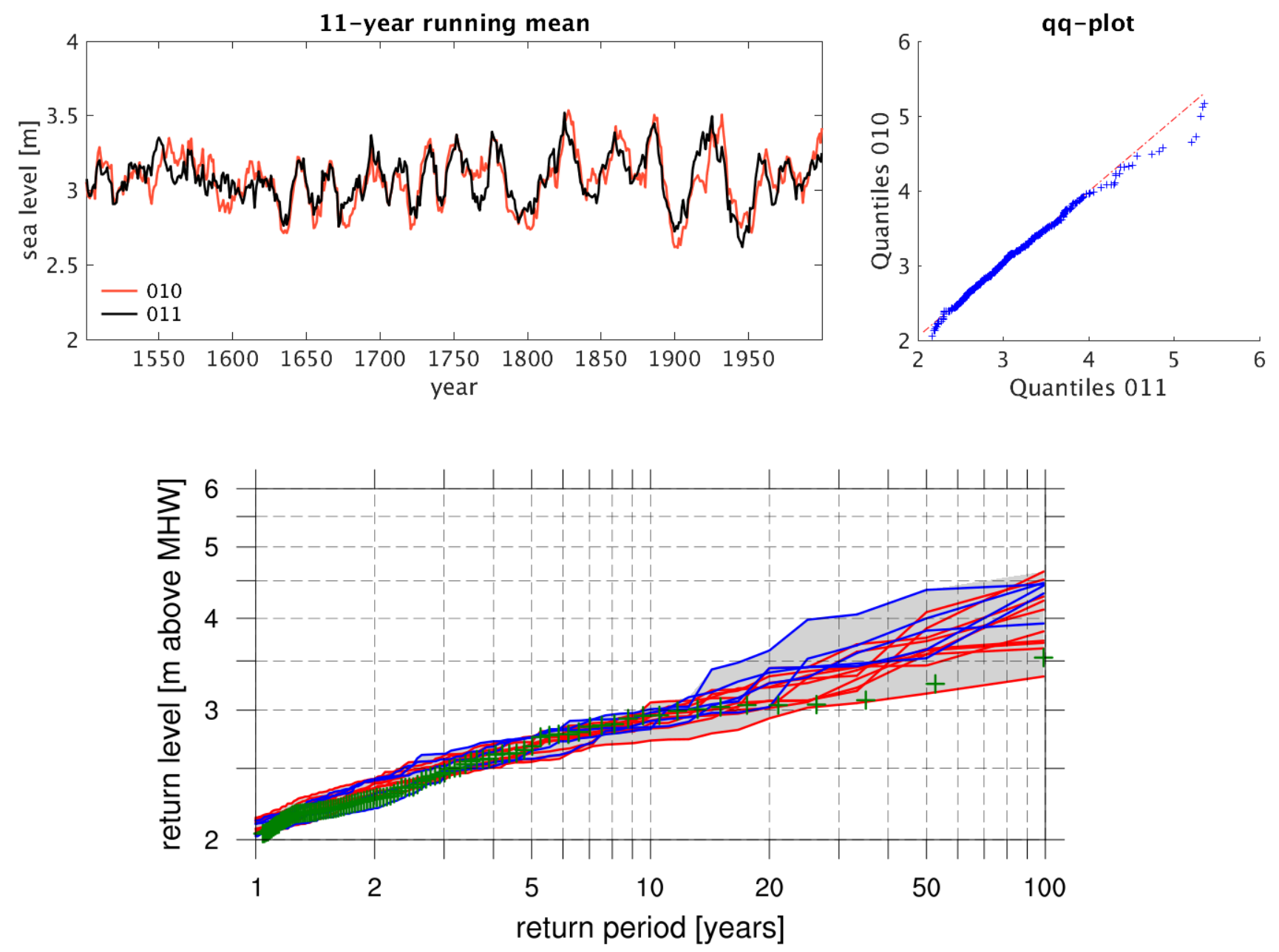

Figure S5. Comparison of ESL at Cuxhaven between runs 010 and 011 for the years 1500-2000. Left: Time series for 11-year running means. Right: Quantile-Quantile plot. Bottom: Return value plot of simulated sea level at Cuxhaven [m over MHW] (colored lines representing 100year long segments of the full 1000 years) against observations from tide gauges (green crosses) for run 011 (red, 1000-2000) and for run 010 (blue, 1500-2000) 


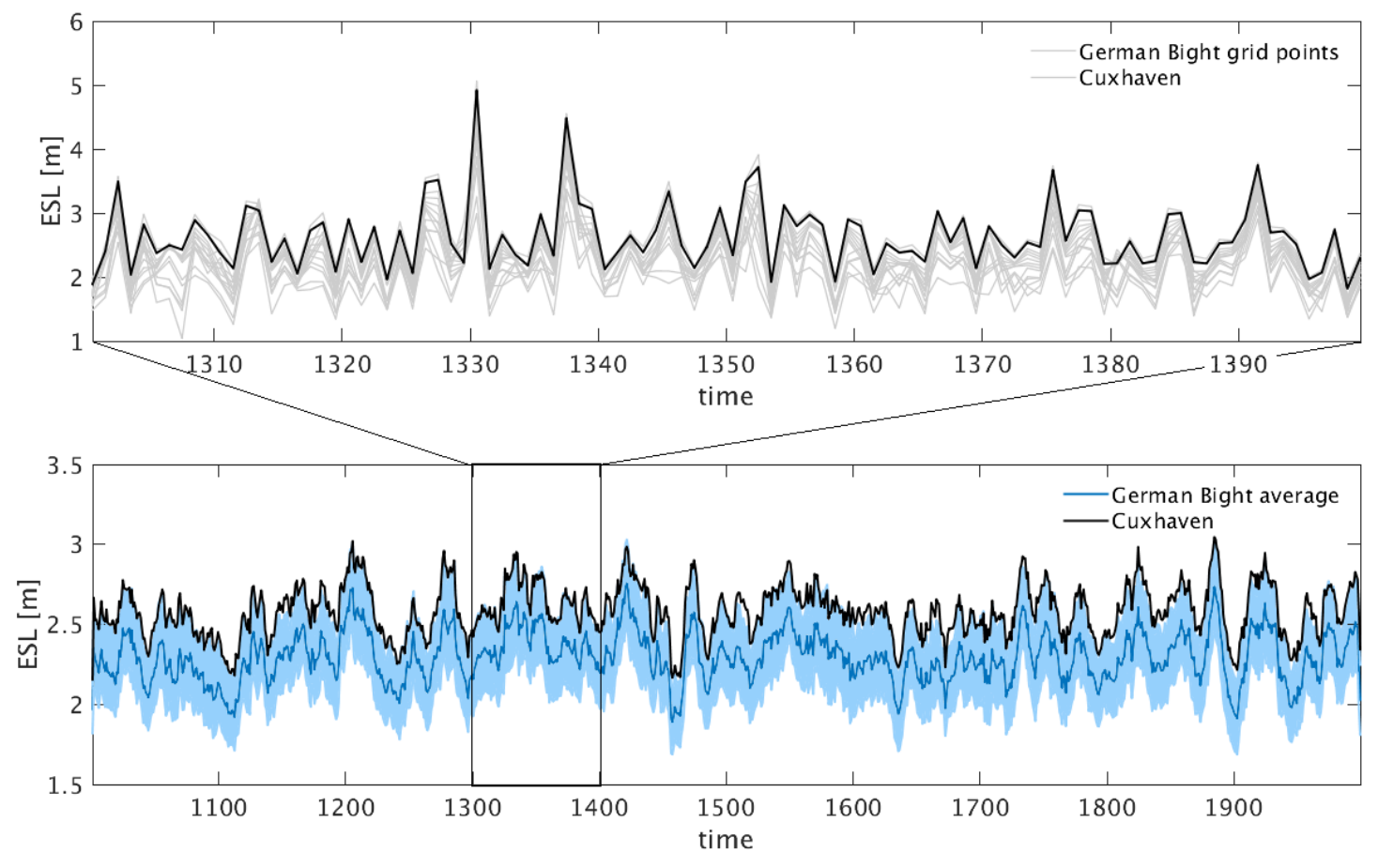

Figure S6. Comparison of ESL along the German Bight. Top: Annual maximum sea level at Cuxhaven in comparison to other gridpoints at the German Bight coast (grey). Bottom: 11-year running mean of the annual maximum sea level at Cuxhaven (black) and the spatially aggregated annual maxima along the German Bight coast (blue) \pm one standard deviation (light blue). 

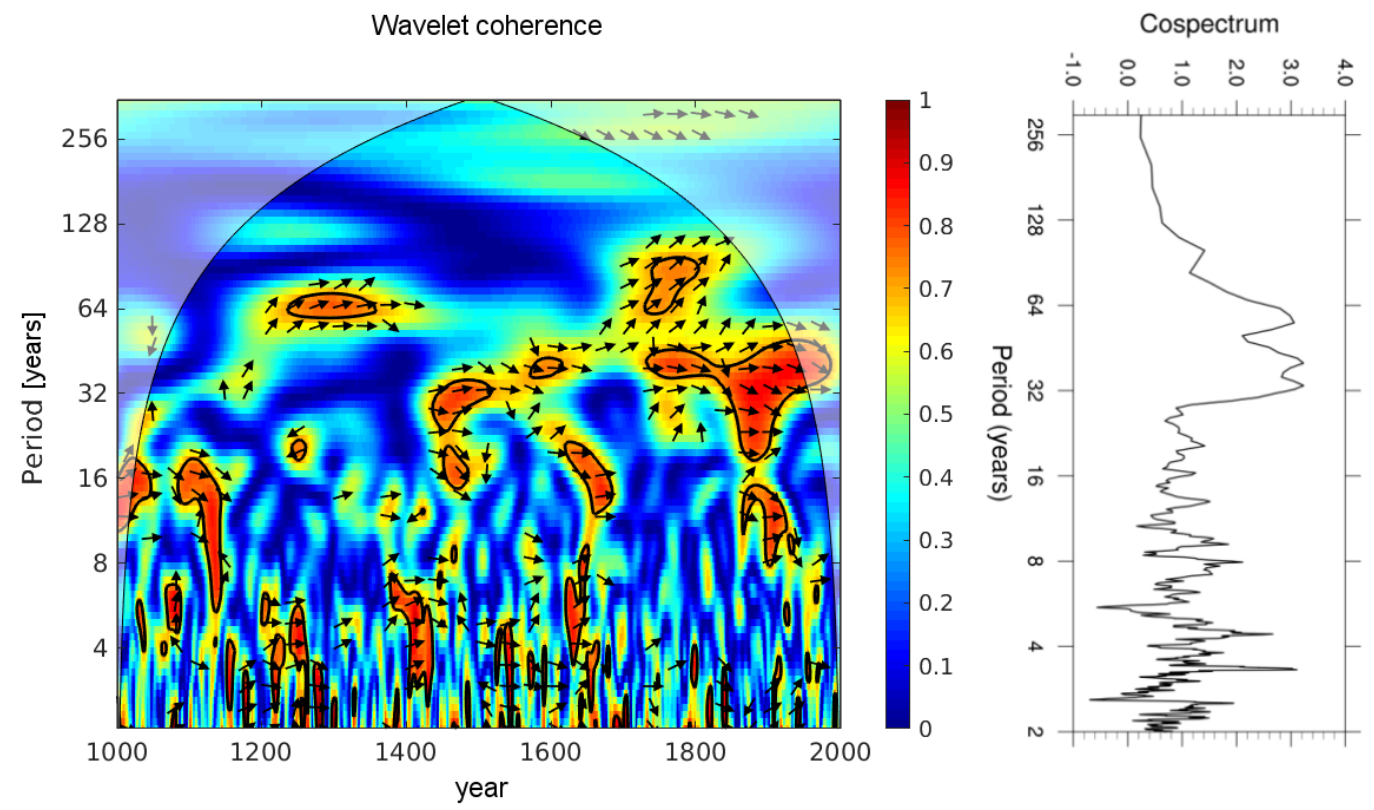

Figure S7. Wavelet coherence and cospectrum of winter median and annual maximum sea level. Arrows to the right (left) indicate a positive (negative) correlation and upward (downward) arrows indicate a lag (lead) of winter median sea level. Thick contours designate the 5\% significance level against red noise, the cone of influence is shown as a lighter shade. 

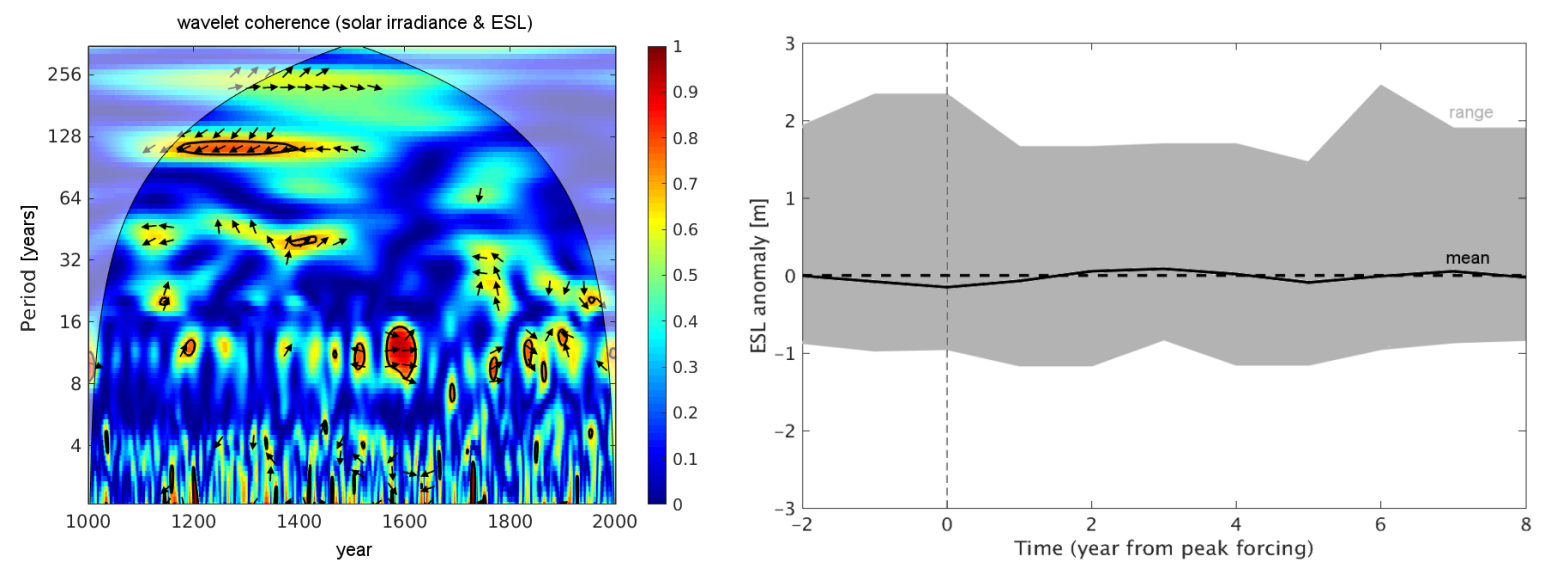

Figure S8. Left: Wavelet coherence between solar irradiance and ESL. Arrows to the right (left) indicate a positive (negative) correlation and upward (downward) arrows indicate a lag (lead) of solar irradiance. Right: Mean lagged ESL after major volcanic activity (perturbance $\left.>4 \mathrm{Wm}^{-2}\right)$. 